\title{
Efficiency of crosses selection for yield in red rice through diallel analysis
}

\author{
Ricardo Montalván Del Águila ${ }^{1 *}$ (i) and Edson Ferreira da Silva² ${ }^{[}$ \\ ${ }^{1}$ Embrapa Meio Norte, Av. Duque de Caxias, 5650 - 64008-780 - Teresina, PI - Brazil. ²Universidade Federal Rural de Pernambuco, \\ Depto. de Biologia, Rua Dom Manoel de Medeiros, s/n - 52171-900 - Recife, PE - Brazil. *Corresponding author: \\ ricardo.aguila@embrapa.br
}

\begin{abstract}
Diallel analysis is a methodology used in the genetic improvement of plants. One of its main purposes is to provide subsidies for early identification of promising crosses for the development of high yielding inbred lines. Several articles have been published in diallel analysis, and many recommendations were made either for the selection of certain crosses of lines for hybrids or for the development of competitive inbred lines. However, articles about the validation of information predicted by these analyses and the results in the field are scarce or nonexistent. The objective of this article was to validate diallel analysis using model IV of Gardner and Eberhart published in 1966, a methodology recommended to identify promising crosses among developed inbred lines in red rice. We compared the recommendations of the diallel analysis crosses with the process end the result of inbreeding generations. Recommended crosses by the diallel analysis were different from those obtained after generations of self-fertilization and selection. However, two of the four selected parents were matched. Considerations were made about the accuracy of diallel analysis and the need to validate in practice methodologies that theoretically are of great value.
\end{abstract}

Keywords: Reliability, plant breeding, prediction, diallelic cross, parent selection, combination ability.

\section{INTRODUCTION}

Diallelic cross analysis is a widely used methodology for the genetic improvement of plants (Chukwu, Okporie, Onyishi, Ekwu, \& Nwogbaga, 2016; Fasahat, Rajabi, Rad, \& Derera, 2016). In the study of the gene effects of the characters, more specifically in allogamous plants, it provides subsidies in the selection of parents to obtain commercial hybrids. In autogamous plants, it is also useful for the early identification of promising crosses aiming at the development of new inbred lines with more possibilities to become cultivars (Vencovsky \& Barriga, 1992; Cruz et al., 2012).

Diallel analysis methodology consists of the study of a set of hybrids that may include the respective parents, segregant generations as $\mathrm{F}_{2}{ }^{\prime}, \mathrm{F}_{3}{ }^{\prime}$, etc., backcrosses and others. Common diallel anaylsis procedure are Hayman (1954a), Hayman (1954b), Griffing (1956) and Gardner and Eberhart (1966). Evaluation of crosses allows the estimation of the value per se of the parents and their combinatorial abilities, enabling the identification of the best populations derived from them regarding the genetic diversity (Hallauer, Carena, \& Miranda-Filho, 2010).

Several articles have been published using diallel analysis, and many recommendations were made for the selection of certain crosses of inbred lines in order to obtain commercial hybrids or to develop competitive pure lines (Borghi, \& Perenzin, 1994; Mutimaamba et al., 2017). However, articles about the confrontation of predicted information from these analyzes and from those observed after the generations of selffertilization are scarce or nonexistent. Nevertheless, there are still important questions and some restrictions on the diallel use as a source of information that may contribute to breeding programs (Baker, 1978). The objective of this paper was to validate the recommendations of promising crosses of a diallel analysis using the methodology of model IV of Gardner and Eberhart (1966), performed in red rice (Figure 1) by Pereira, Morais and Breseghello ( 2008). 


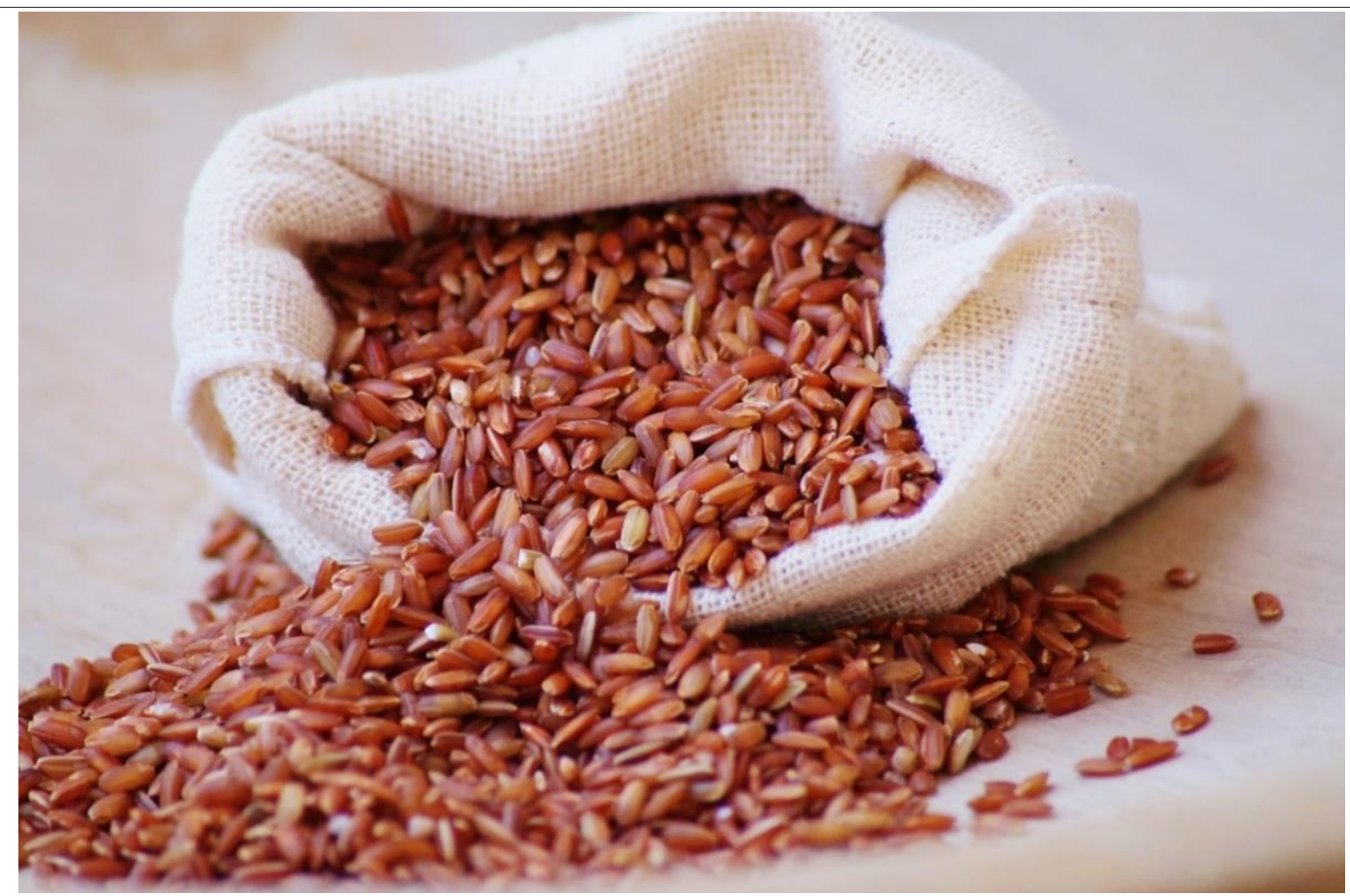

Figure 1. Illustrative image of the red rice grains used in the experiment.

Photo: By Maria Eugenia Ribeiro, Embrapa Meio-Norte.

\section{MATERIALS AND METHODS}

Ten most commonly grown cultivars of red rice from the Northeast region of Brazil (named parents), three from the state of Alagoas (AL01, AL03, and AL04) and seven from the state of Paraiba (PB04, PB05, PB09, PB10, PB11, PB12 and PB13), were crossed in a complete $10 \times 10$ diallel design, without reciprocals, for the implementation of a breeding program. Parents and their $45 F_{1}$ were evaluated in a field experiment in the second half of 2005, while parents and their $45 F_{3}$ in the second half of 2006 regarding their agronomic characteristics. All two field experiments were in a randomized complete block design with three replicates in Teresina, Piauí state, Brazil $\left(5^{\circ} 09^{\prime} \mathrm{S} ; 42^{\circ} 48^{\prime} \mathrm{W}\right.$, considered an tropical wet and dry climate with an altitude of $72 \mathrm{~m}$ and the following average characteristics in the second semester: temperature $28^{\circ} \mathrm{C}$, relative humidity $63 \%$ and total rainfall $201 \mathrm{~mm}$ ). For the diallel analysis, the ten parents and an additional cultivar (PB 01) were used as common treatments in the experimental evaluations involving the $F_{1}$ and $F_{3}$ generations.

$\mathrm{F}_{1}$ generation experiment was grown under controlled flood irrigation with water flood control, in oneline plots with 12 transplanted seedlings, spaced $0.25 \mathrm{~m}$ between plants and $0.30 \mathrm{~m}$ between rows, whose sample area was the ten central plants of the line $\left(0.75 \mathrm{~m}^{2}\right) . F_{3}$ experiment was carried out under irrigated conditions using direct seeding with plots of three $5 \mathrm{~m}$ rows spaced $0.30 \mathrm{~m}$ at a density of 20 seeds per linear meter. This special condition in the development of the $F_{1}$ generation was necessary to avoid plant losses due to the difficulty in obtaining $F_{1}$ crosses in autogamous plants. The favorable condition was corrected in the statistical analysis by adjusting the use of common treatments, as pointed out previously. The inbreeding generations process $\left(F_{2}, F_{3}\right.$, etc.) were grown twice a year, in the rainy season and in the dry season with flood irrigation and a plot of $1.5 \mathrm{~m}^{2}$ per treatment was used.

Diallel analysis of grain yield using model IV of Gardner and Eberhart (1966) methodology resulted in recommendations on promising crosses in the generation of high-yielding inbred lines described in Pereira et al. (2008). However, prior to this analysis, a soft selection of crosses for advancement to the $F_{4}$ generation was initiated in the $\mathrm{F}_{3}$ (in 2006). Subsequently, the process of advancing generations through the pedigree method with a mild selection for smaller plants was followed, ignoring the recommendations of the diallel analysis, whose results were ready only two years after the $F_{3}$ generation. Finally, in the $F_{8}$ generation, two lines were identified to assess their value for cultivation and use. 


\section{RESULTS AND DISCUSSION}

Table 1 shows the analysis of the variance of the diallel analysis partitioned into the main sources of variation. Diallel analysis of ten parental red rice carried out by Pereira et al. (2008) concluded that the greatest effects of general combining ability were on AL03, PB05 and PB13 parents and the promising crosses for the generation of new high-yielding red rice lines would be PB05 x PB10 and AL03 x PB13. However, a different result was found at the end of the inbreeding generation, since the selected crosses that originated a pure line of value for cultivation and use assays were PB04 x PB10 and PB05 x PB09, as presented in Table 2.

Table 1. Analysis of the variance of the diallel analysis of grain yield in $g\left(\mathrm{~m}^{2}\right)^{-1}$ partitioned into the main sources of variation (Pereira et al., 2008).

\begin{tabular}{lcccc}
\hline Source of variation & $\begin{array}{c}\text { Degrees of } \\
\text { freedom }\end{array}$ & Sum of squares & Mean squares & $\mathrm{F}$ \\
\hline Treatments & 99 & 10.696 .314 & 108.044 & $3.27^{* *}$ \\
\hline Cultivars & 9 & 656.860 & 72.984 & $2.21^{* *}$ \\
\hline Heterosis in $\mathbf{F}_{\mathbf{1}}$ & 45 & 3.134 .716 & 69.660 & $10.44^{* *}$ \\
\hline Average heterosis in $\mathbf{F}_{\mathbf{1}}$ & 1 & 344.509 & 344.509 & $5.38^{* *}$ \\
\hline Varietal heterosis in $\mathbf{F}_{\mathbf{1}}$ & 9 & 1.597 .049 & 177.450 & $2.32^{* *}$ \\
\hline Specific heterosis in $\mathbf{F}_{\mathbf{1}}$ & 35 & 2.677 .344 & 76.496 & $1.61^{* *}$ \\
\hline Heterosis in $\mathbf{F}_{\mathbf{3}}$ & 45 & 2.384 .444 & 52.988 & $0.62^{\text {ns }}$ \\
\hline Average heterosis in $\mathbf{F}_{\mathbf{3}}$ & 1 & 20.430 & 20.430 & $2.07^{* *}$ \\
\hline Varietal heterosis in $\mathbf{F}_{\mathbf{3}}$ & 9 & 614.355 & 68.262 & $1.48^{*}$ \\
\hline Specific heterosis in $\mathbf{F}_{\mathbf{3}}$ & 35 & 1.709 .850 & 48.853 & - \\
\hline Residue & 308 & 6.864 .699 & 33.003 & \\
\hline *Significant at the 05 probability & level **Significant at the 01 probability level ${ }^{\text {ns not significant }}$
\end{tabular}

*Significant at the .05 probability level. ${ }^{* *}$ Significant at the .01 probability level. ${ }^{\text {ns }}$ not significant.

The choice of the promising crosses for diallel analysis followed the recommendations in the literature (Gardner \& Eberhart, 1966; Vencovsky \& Barriga, 1992; Cruz, Regazzi, \& Carneiro, 2012), in which the value of $g$ (with its components $(1 / 2) v$ and $h$ ) and parental productivity are presented in Table 3 . The $v$ effect refers to the value per se, and $h$ effect is related to the diversity of the parents and the effect of gene dominance.

\section{Genetic analysis of crosses considered the most promising by the diallel analysis}

Selection of the AL03 $\times$ PB13 cross was made according to the theoretical recommendations for diallel analysis. These parents have the greatest positive deviations of the general combining ability $(g)$, and were statistically different from zero, as well as the most productive (Table 3 ). In turn, in the selection of the PB05 $\times$ PB10 cross, it was verified that PB05 has the third largest value of $g$. It was statistically different from zero, and also the third place in productivity. However, PB10 was not an interesting parent, since its $g$ ranked seventh and sixth in productivity. In addition, because of its $g$ was not significant, it can be inferred that no evidence was found that its effect is different from zero (Christensen, 1996; Gomes, 2009). However, the choice of PB10 as a pair of PB05 was due to its excellent performance in specific heterosis with PB5, having reached the second largest positive and important deviations in $F_{1}$ and $F_{3}$ (Table 3 ).

Further clarification on the choice of promising crosses was needed by taking advantage of the partitioning of the general combining ability of the parents into their components $(1 / 2) v$ (cultivar effect) and varietal $h$ (heterosis effect: difference between the mean of the varietal and the general heterosis) (Table 3). 
Table 2. Evolution of selections in segregating self-fertilizing generations.

\begin{tabular}{|c|c|c|c|c|c|}
\hline$F_{3}$ & $\mathrm{~F}_{4}$ & $\mathrm{~F}_{5}$ & $\mathrm{~F}_{6}$ & $\mathrm{~F}_{7}$ & $\mathrm{~F}_{8}$ \\
\hline & $\begin{array}{c}\text { AL01 x (AL03, AL04, PB04, } \\
\text { PB05, PB10) }\end{array}$ & AL01 x PB04 & $\begin{array}{c}\text { AL01 x PB10, } 4 \\
\text { plants }\end{array}$ & - & - \\
\hline & $\begin{array}{c}\text { AL03 x (AL04, PB04, PB05, } \\
\text { PB09, PB10) }\end{array}$ & AL01 x PB10 & - & - & - \\
\hline & \multirow[t]{4}{*}{$\begin{array}{c}\text { AL04 x (PB04, PB05, PB09, } \\
\text { PB10, PB11) }\end{array}$} & AL04 x PB4 & $\begin{array}{c}\text { AL04 x PB04, } 5 \\
\text { plants }\end{array}$ & - & - \\
\hline & & AL04 x PB5 & $\begin{array}{l}\text { AL04 x PB5, } 7 \\
\text { plants }\end{array}$ & & - \\
\hline & & AL04 x PB09 & - & - & - \\
\hline & & AL04 x PB10 & $\begin{array}{c}\text { AL04 } \times \text { PB10, } 4 \\
\text { plants }\end{array}$ & - & - \\
\hline & PB04 x (PB10) & PB04 x PB10 & $\begin{array}{c}\text { PB04 } \times \text { PB10, } 3 \\
\text { plants }\end{array}$ & $\begin{array}{l}\text { PB04 } \times \text { PB10, } 5 \\
\text { plants }\end{array}$ & $\begin{array}{l}1 \text { inbred } \\
\text { line }\end{array}$ \\
\hline & PB05 x PB09 & PB05 x PB09 & $\begin{array}{l}\text { PB05 x PB09,3 } \\
\text { plants }\end{array}$ & $\begin{array}{l}\text { PB05 } \times \text { PB09, } 5 \\
\text { plants }\end{array}$ & $\begin{array}{l}1 \text { inbred } \\
\text { line }\end{array}$ \\
\hline & PB12 x PB04 & PB12 x PB04 & $\begin{array}{l}\text { PB12 } x \text { PB04, } 3 \\
\text { plants }\end{array}$ & - & - \\
\hline & PB13 x (AL01, AL03, PB05) & PB13 x AL01 & $\begin{array}{l}\text { PB13 } \times \text { AL01, } 2 \\
\text { plants }\end{array}$ & - & \\
\hline $\begin{array}{c}45 \\
\text { crosses }\end{array}$ & 21 crosses & 10 crosses. & $\begin{array}{l}8 \text { crosses } \\
\text { (31plants) }\end{array}$ & $\begin{array}{l}2 \text { crosses } \\
\text { (10plants) }\end{array}$ & $\begin{array}{c}2 \text { crosses } \\
(2 \text { inbred } \\
\text { lines })\end{array}$ \\
\hline
\end{tabular}

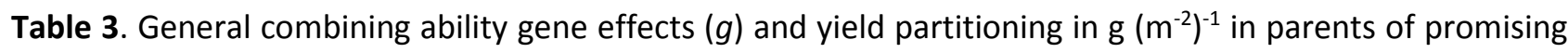
crosses based on Pereira et al. (2008).

\begin{tabular}{lcccccccc}
\hline Crosses & Parents & $g$ & $1 / 2 c$ & $h_{\mathrm{F} 1}$ & $h_{\mathrm{F} 3}$ & $h$ & $1 / 2 c \%$ & $h \%$ \\
\hline AL03 x PB13 & AL03 & $71.8^{* *}$ & $85.2^{*}$ & $104.1^{*}$ & $-131.0^{*}$ & -13.4 & 86 & 14 \\
& & & & & & & & \\
\hline & PB13 & $66.7^{*}$ & $82.7^{*}$ & $38.3^{\text {ns }}$ & $-70.5^{\text {ns }}$ & -16.1 & 84 & 16 \\
\hline PB05 x PB10 & PB5 & $64.7^{*}$ & $39.3^{\text {ns }}$ & $33.6^{\text {ns }}$ & $17.2^{\text {ns }}$ & 25.4 & 61 & 39 \\
\hline & PB10 & $19.8^{\text {ns }}$ & $-0.9^{\text {ns }}$ & $-22.8^{\text {ns }}$ & $64.2^{\text {ns }}$ & 20.7 & 4 & 96
\end{tabular}

c cultivar effect, $h_{\mathrm{F} 1}$ heterosis effect in $\mathrm{F}_{1}, h_{\mathrm{F} 3}$ heterosis effect in $\mathrm{F}_{3}, h$ heterosis effect calculated as $1 / 2\left(h_{\mathrm{F} 1}+h_{\mathrm{F} 3}\right), 1 / 2 \mathrm{c} \% 1 / 2$ $c$ as a percentage of the $g$ effect, $h \% h$ as a percentage of the g effect. ${ }^{\text {ns }},{ }^{*}$ and ${ }^{* *}$; nonsignificant and significant at 5 and $1 \%$ probability by the $t$ test, respectively.

\section{Cross AL03 x PB13}

In agreement with the significance of $g$ of the parentals of this cross, their estimates of $(1 / 2) v$ are also positive, of great magnitude and statistically different from zero. In addition, varietal heterosis effect of ALO3 is greatly and of the greatest magnitude in both $F_{1}$ and $F_{3}$, although it assumes opposite directions, on the positive side on $F_{1}$ and negative on $F_{3}$. Thus, the contribution of $h$ to $g$ in this parent is only $14 \%$ and remains $86 \%$ for $1 / 2 v$, which is theoretically very interesting due to $v$ related to the additive effects of the genes, reinforcing the choice of this parent. In the case of PB13 parent, the $1 / 2 v$ effect is positive, of great magnitude and very similar to the first one, contributing with $84 \%$ of the value of $g$, whereas deviations of 
varietal heterosis effect were not detected as significant in the precision conditions of the experiment. Thus, it is emphasized that at AL03 $\times$ PB13 cross, the specific heterosis in $F_{1}$ and $F_{3}$ were of small magnitude and not statically different from zero.

\section{Cross PB05 x PB10}

Analyzing the PB5 $\times$ PB10 cross, it was verified that in PB05 parent, despite statistical significance for $g$ due to those infrequent situations, it was not possible to detect that its components are different from zero. Moreover, PB10, on the other hand, did not have a noticeably $g$ effect and also its components followed the same trend. Considering these facts, it is estimated that the PB5 $\times$ PB10 crossing was due to the merits of PB05 regarding grain yield (third place), magnitude and significance of its $g$ (also third place).

\section{Genetic analysis of selection crosses with better performance on selection of promising lines in practice.}

The crosses that, at the end of the generations by successive self-fertilization, generated inbred lines for Value for Cultivation and Use test were selected from the PB04 x PB10 and ALO4 x PB05 crosses whose genetic analyzes are shown in Table 4.

Table 4. General combining ability $(g)$ gene effects and partitioning of yield in $g\left(\mathrm{~m}^{2}\right)^{-1}$ of parents of crosses identified after generation of inbreeding and selection of promising inbred lines.

\begin{tabular}{lcccccccc}
\hline Crosses & Parents & $g$ & $1 / 2 \mathrm{C}$ & $h_{\mathrm{F} 1}$ & $h_{\mathrm{F} 3}$ & $h$ & $1 / 2 c \%$ & $h \%$ \\
\hline PB04 x PB10 & PB04 & $38.8^{\text {ns }}$ & $-39.2^{\text {ns }}$ & $56.0^{\text {ns }}$ & $100.1^{*}$ & $78.0^{\text {ns }}$ & 33 & 67 \\
& & & & & & & & \\
\hline & PB10 & $19.8^{\text {ns }}$ & $-0.9^{\text {ns }}$ & $-22.8^{\text {ns }}$ & $64.2^{\text {ns }}$ & 20.7 & 4 & 96 \\
\hline AL04 x PB05 & AL04 & $-136.1^{* *}$ & $15.5^{\text {ns }}$ & $-239.2^{* *}$ & $-63.9^{\text {ns }}$ & -151.5 & 9 & 91 \\
& & & & & & & & \\
\hline & PB5 & $64.7^{*}$ & $39.3^{\text {ns }}$ & $33.6^{\text {ns }}$ & $17.2^{\text {ns }}$ & 25.4 & 61 & 39
\end{tabular}

$c$ cultivar effect, $h F_{1}$ heterosis effect in $\mathrm{F}_{1}, h_{\mathrm{F} 3}$ heterosis effect in $\mathrm{F}_{3}, h$ heterosis effect calculated as $1 / 2\left(\mathrm{~h}_{\mathrm{F} 1}+\mathrm{h}_{\mathrm{F} 3}\right), 1 / 2 c \%$ $1 / 2 c$ as a percentage of the $\mathrm{g}$ effect, $h \% h$ as a percentage of the $g$ effect. ${ }^{\text {ns }},{ }^{*}$ and ${ }^{* *}$; nonsignificant and significant at 5 and $1 \%$ probability by the $t$ test, respectively.

\section{Cross PB04 x PB10}

Diallel analysis showed that the g effects of parents of this cross were of small magnitude, not statistically

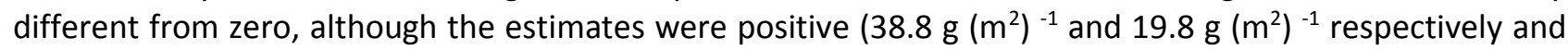

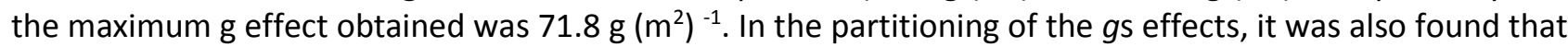
the $1 / 2 v$ effects also were not statistical significant. However, heterosis of $F_{3}\left(h_{F 3}\right)$ of PB04 was the largest and unique positive and statistically different from zero of the heterosis effects in this generation, and the percentage participation of $h$ in $g$ was 67\% in this parent. This seems to indicate that PB04 is not attractive to be selected. This is due to a low $g$, grain yield basically dependent on varietal heterosis demonstrating its low accumulation of additive gene effects.

\section{Cross AL04 x PB05}

AL04 occupies the fourth position in yield productivity. It has a statistically significant $g$, however negative, and is theoretically not interesting due to the fact that this parent has a high magnitude of additive gene effects contrary to productivity. The partitioning of $g$ indicates that heterosis in $\mathrm{F}_{1}\left(h_{\mathrm{F} 1}\right)$ has the greatest negative, highly marked deviation. When added to the effects of $h_{\mathrm{F} 3}, h$ contributes $91 \%$ to the $g$ value, remaining only $9 \%$ for the additive gene effects (Table 3). Analyzing $h$ in more details, in this case, we can see that its deviation $h_{F 1}$ is highly noticeably, of greater negative magnitude among all of them. Its $h_{\mathrm{F} 3}$, also negative. Based on this information, it can be said that, besides the fourth position in productivity, this parent has no other genetic characteristics revealed by the diallel analysis that can make it attractive to be selected. 
The PB05, one of the parents selected at the crosses considered as promising by the diallel analysis, has been described as unattractive, according to the recommendations for the parent selection. But PB05 has some merits: it is a productive parent (third in the classification) with a good $g$ effect, the third largest positive and noticeably $g$. However, it failed to demonstrate statistical significance at $1 / 2 v$ and $h$ components.

In the absence of agreement between the recommendations for the diallel analysis and the results of promising crosses selection after the generation of inbreeding, the selection of inbred lines valuable for cultivation and use tests, performed in practice, can be attributed to:

Selection of families performed during generations of the inbreeding process. In the $\mathrm{F}_{3}$ generation, $47 \%$ of the crosses were chosen, excluding explicitly defective individuals. In the selection of $F_{4}, 48 \%$ of the remaining were chosen. In $\mathrm{F}_{5}, 80 \%$ of the remnants were separated, being more common than that in the latter generation, where, in fact, the selection of plants was carried out. It is worth emphasizing that the effects of dominance can mask the vigor of the plants to be selected. This occurs especially in the first generations of self-fertilization, enabling the election of families with attributes to be diminished in subsequent inbreeding generations.

Another important drawback of early selection is the elimination of crosses in the first selections. In the present research, the promising crossover identified by the diallel analysis, PB05 x PB10 was eliminated from the inbreeding process in $\mathrm{F}_{3}$, and the other AL03 $\times$ PB13 was excluded in $\mathrm{F}_{4}$. However, it is important to emphasize that the attributes that guided early selection, such as excessive height of plants, very long cycle and type of grain, have high heritability known as unfavorable to the crop or preferred by the traditional consumer. Another aspect that justifies this selection is the fact that red rice breeding in Brazil is recent, and purification actions towards known harmful characteristics are necessary. Therefore, this can be justified by the soft selection practiced in the generations $F_{2}$ to $F_{4}$.

Accuracy of the estimates that supported the recommendations of promising crosses is not optimal. These originated from an experiment with $F_{1}$ and parents in one year and one location, with parents and $F_{3}$ in another year, yet in the same location. More accurate diallel experiments involve several sites and two years, which, in practice, is difficult to perform due to difficulties in obtaining seeds of crosses in autogamous plants. With repeated experiments in places and years, it is possible to isolate the sources of genotype interaction variation within environments and years from the residue, as well as to improve the accuracy of estimates of the general and the specific combining ability of the crosses. Also, averages and deviations $(g, 1 / 2 v, h)$ derive from a greater number of observations. In the experiment under consideration, the coefficient of variation was $22 \%$, considered relatively high, and thus, its accuracy was considered low. Therefore, the relevance of the analyzed effects needs to be better evaluated by analyzing the relative dispersion of the magnitude of the estimated effects according to Cox (1982) (Tables 5 and 6). In addition, according to Christensen (1996), coefficient intervals are more valuable than simply reporting the estimates, since it provides an idea of the amount of error associated with the estimates.

Data in Table 5 show that the general combining abilities of parents of crosses considered to be promising by diallel analysis have moderately dispersions, around $+-40 \%$ of their estimates (excluding PB10). Thus,

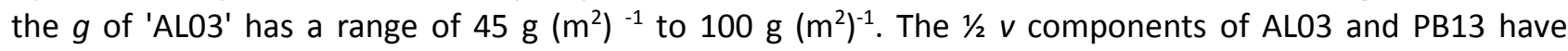
dispersions similar to those of their $g$ estimates, always presenting positive values, reinforcing the idea that the choice of this cross is adequate.

At the second cross selected in this group, PB05 $\times$ PB10, PB05 reveals dispersion for $g$ also similarly in percentage to the parents of the first selected cross. However, when observing the partitioning of $g$, new information arises. The estimate of $1 / 2 v$ has a very broad dispersion of $+-98 \%$ of their estimate, ranging

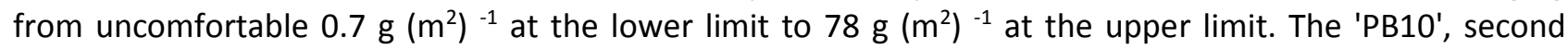
parent of this cross, far exceeded the magnitude of its dispersion when comparing it with the first three

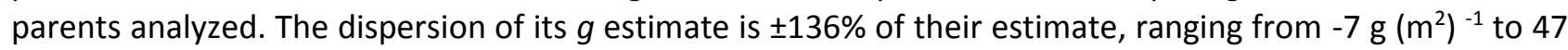
$\mathrm{g}\left(\mathrm{m}^{2}\right)^{-1}$ and may assume negative values. In turn, the dispersion of its $1 / 2 v$ estimate reaches exceptionally

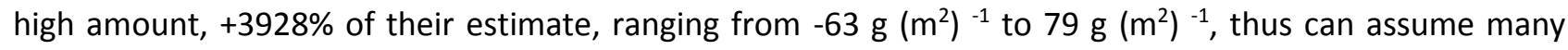
negative values.

Next considerations on the dispersions of estimates of the general combining ability (and their components) of the parents of crosses effectively selected after self-fertilization generations are made (Table 6). 


\section{Cross AL04 x PB05}

The CGA estimate of AL04 $\left(-136.1^{* *}\right)$ was highly significant and negative and with the lowest level of dispersion of all estimates in Tables 4 and 5 (Standard deviation of $g$ percent $g=21 \%$ ). This would indicate the possession of genes that contribute very negatively to productivity which is not at all attractive in parent selection. Even worse, the dispersion of this CGA $(g)$ only covers negative values ranging from $-165 \mathrm{~g}$ $\left(\mathrm{m}^{2}\right)^{-1}$ to $-107 \mathrm{~g}\left(\mathrm{~m}^{2}\right)^{-1}$. In the GCA partition, it is found that the estimate of $1 / 2 \vee$ has a huge dispersion $( \pm 228 \%)$ and that can be influenced by the absence of statistical significance of $g$. We then used the effect of heterosis $(h)$ to try to explain the high statistical significance of negative CGA of this cultivar. Its varietal heterosis in $\mathrm{F}_{1}$ was highly negative $\left(-239.2 * * \mathrm{~g}\left(\mathrm{~m}^{2}\right)^{-1}\right.$, while its heterosis in $\mathrm{F}_{3}$ was not notable (Pereira et al., 2008). Thus, the component $h$ would explain the negative statistical significance of CGA. However, the low precision level of the $\mathrm{F}_{3}$ heterosis effect may have had a negative influence on the detection of significance.

The parent, PB05, has been previously analyzed as being one of the parents of one of the crosses recommended by diallel analysis, whenever crossed with PB10. However, the presence of this parent, which has one of the best CGA, would give some theoretical support to the fact that the AL05 x Pb05 cross had originated the selection of an inbred line value for cultivation and use test in practice. Also, it suggests that the crosses selected by the diallel analysis under analysis, are not completely unfocused from the performance of crosses in the production of more productive lineages in the process of advancement of generations of inbreeding.

\section{Cross PB04 x PB10}

PB04 and PB10 are parents with relatively few merits. In productivity, they are below the group average. The diallel analysis showed that their CGAs were of small magnitude, not statistically different from zero,

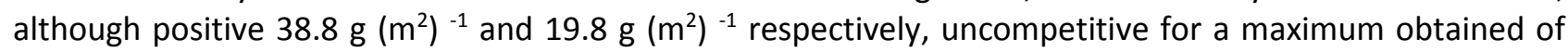

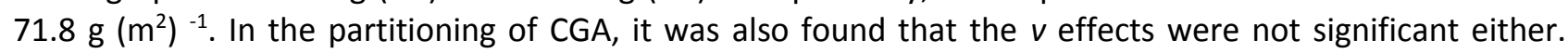
However, heterosis of $\mathrm{F}_{3}\left(\mathrm{~h}_{\mathrm{F}}\right)$ from 'PB04' was the largest and single, positive and different from zero among evaluated genotypes and percentage participation of $h$ in CGA was 67\% in this genotype (Table 3). This seems to indicate that PBO4 has a CGA low in magnitude and basically dependent on varietal heterosis. Such would demonstrate its low accumulation of additive effects. However, it is good to consider that the information of the dispersion of the $g$ and $v$ effects serve to indicate that the low level of precision of these estimates explains, in part, such absence of significance (Table 6).

\section{Failure of assumptions of diallel analysis}

Genetic interpretation of the results of diallel analysis is valid only if some assumptions about the parents are true. These assumptions were discussed by several authors (Kempthorne, 1956; Baker, 1978; Christie \& Shattuck, 1992, among others). There are critical issues on diallelic experiments that meet some of these requirements. The following aspects are pointed out:

Establish that the genes are distributed independently is unsustainable (Kempthorne, 1956; Nassar, 1965). This assumption implies that the presence or absence of an allele at a particular locus is statistically independent of the presence or absence of an allele at any other locus. Failure of this assumption may result from genetic linkage in the population from which the parents were chosen. In turn, Baker (1978) concluded that assuming that genes are distributed independently in the parent of a diallel is unrealistic. However, he also said that there are contradictory reports of the effects of failures on estimates of both general and specific combining ability.

Absence of epistasis: According to Baker (1978) assumption of no epistasis can often be incorrect. Epistasis affects mean square estimates of general and specific combination ability, variances, and effects in an unpredictable manner. However, Nkalubo, Melis, Derera, Laing and Opio (2009) working with resistance to anthracnose in beans and not in yield in red rice, as in this case, were not conclusive about the action of epistasis in this character.

No genotype $x$ environment interaction: According to Fasahat et al. (2016), this assumption is often not calculated to know the role of the genotype $x$ environment interaction in combining ability. This can only be verified by evaluating diallel crosses in at least three environments, a requirement that was not observed in the present experiment. This leads to another practical aspect of using diallels as tools in selecting promising crosses in breeding programs, due to the high control cost of this assumption. 
Table 5. General combining ability, the standard deviation of $g$ in percent of $g$ and dispersion of general combining ability $(g)$ and $1 / 2$ cultivar effects $(1 / 2 v)$ of parents from promising crosses of a red rice diallel

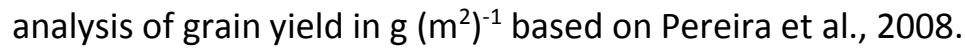

\begin{tabular}{|c|c|c|c|c|c|c|c|}
\hline Crosses & Parents & $\begin{array}{c}\text { General } \\
\text { combining } \\
\text { ability }(\mathrm{g})\end{array}$ & $\begin{array}{l}\text { Standard } \\
\text { deviation of } \\
\mathrm{g} \text { in per } \\
\text { cent of g } \\
(\mathrm{sg} \%)\end{array}$ & $\begin{array}{l}\text { Dispersion } \\
\text { (g-sg-g+sg) }\end{array}$ & $1 / 2 C$ & $\begin{array}{c}\text { Standard } \\
\text { deviation of } \\
1 / 2 \text { c in per } \\
\text { cent of } 1 / 2 \text { c } \\
(\mathrm{s} 1 / 2 \mathrm{C} \%)^{\S}\end{array}$ & $\begin{array}{l}\text { Dispersion }(1 / 2 c \\
s 1 / 2 c-1 / 2 c+s 1 / 2 c)\end{array}$ \\
\hline AL03 $x$ & AL03 & $71.8^{* *}$ & 38 & $45-100$ & $85.2^{*}$ & 41 & $50-121$ \\
\hline PB13 & PB13 & $66.6^{*}$ & 40 & $40-93$ & $82.7 *$ & 43 & $47-118$ \\
\hline PB05 $x$ & PB5 & $64.7^{*}$ & 40 & $39-91$ & $39.3 \mathrm{~ns}$ & 98 & $0.7-78$ \\
\hline PB10 & PB10 & $19.8^{\text {ns }}$ & 136 & $-7-47$ & $-0.9 n s$ & 3928 & $-36-34$ \\
\hline
\end{tabular}

ns, $*$ and ${ }^{* *} ;$ nonsignificant and significant at 5 and $1 \%$ probability by the $t$ test.

${ }^{5} s 1 / 2 C=\left[(1 / 2)^{2} s^{2} 1 / 2 c\right]^{1 / 2}$.

Table 6. General combining ability, the standard deviation of $\mathrm{g}$ in percent of $\mathrm{g}$ and dispersion of general combining ability $(\mathrm{g})$ and $1 / 2$ cultivar effects $(1 / 2 \mathrm{v})$ of parents of red rice crosses identified after generations of inbreeding and selection of inbred lines of value for cultivation and use test.

\begin{tabular}{|c|c|c|c|c|c|c|c|}
\hline Crosses & Parents & $\begin{array}{c}\text { General } \\
\text { combining } \\
\text { ability (g) }\end{array}$ & $\begin{array}{c}\text { Standard } \\
\text { deviation of g } \\
\text { in percent of } \\
\mathrm{g}(\mathrm{sg} \%)\end{array}$ & $\begin{array}{c}\text { Dispersion } \\
\text { (g-sg-g+sg) }\end{array}$ & $1 / 2 C$ & $\begin{array}{c}\text { Standard } \\
\text { deviation } \\
\text { of } 1 / 2 \mathrm{c} \text { in } \\
\text { percent } \\
\text { of } 1 / 2 \mathrm{C}(\mathrm{s} \\
1 / 2 \mathrm{C} \%)^{\S}\end{array}$ & $\begin{array}{c}\text { Dispersion }(1 / 2 \\
c-s^{1 / 2} \mathrm{C}-1 / 2 \quad c+s^{1 / 2} \\
\text { c) }\end{array}$ \\
\hline
\end{tabular}

\begin{tabular}{cccccccc}
\hline AL04 x & AL04 & $136.1^{* *}$ & 21 & $-165--$ & $15.5^{*}$ & 228 & $-20-51$ \\
\hline PB05 & & & & & & \\
\hline
\end{tabular}

\begin{tabular}{llllllll}
\hline & PB05 & $64.7^{*}$ & 40 & $39-91$ & $39.3^{*}$ & 98 & $0.65-78$ \\
\hline PB04 x & PB4 & $38.8^{\text {ns }}$ & 65 & $13-64$ & - & 90 & $-75-3.9$ \\
\hline
\end{tabular}

PB10

$39.2^{\text {ns }}$

\begin{tabular}{|c|c|c|c|c|c|c|}
\hline PB10 & $19.8^{\mathrm{ns}}$ & 136 & $-7-47$ & $-0.9^{\text {ns }}$ & 3928 & $-36-34$ \\
\hline
\end{tabular}

Restrictions on assumptions must be coupled with limitations on the accuracy of data that is taken in one place, at best, in a few of them and within one or two years. The reason for this is the reduction of costs, time, as well as the possibility of making the use of such predictions attractive. One could not spend much time, money, and effort to obtain data for predictions, if these items were equivalent to the use of generations' advancement methods without using such predictions.

The comment on the usefulness of the diallels is not new, since 1958 (Gilbert, 1958) had already concluded: "The diallel cross offers a means of rationalizing some aspects of plant breeding while keeping the amount of work down to a manageable level. Its utility to the breeder can be exaggerated. The polygene analysis of a diallel cross suffers from several theoretical defects, but in any case its results do not appear to be directly relevant to practical breeding work." Gilbert (1958) ends by indicating that the results 
of a diallel analysis cannot be given as definitive, according to him: "No statistics can replace the breeder's intimate knowledge of his crop but they can help."

\section{CONCLUSIONS}

It was compared the recommendations of the diallel analysis crosses with the process end the result of inbreeding generations. Recommended crosses by the diallel analysis were different from those obtained after generations of self-fertilization and selection. However, two of the four selected parents were matched. Considerations were made about the accuracy of diallel analysis and the need to validate in practice methodologies that theoretically are of great value.

\section{ACKNOWLEDGEMENTS}

The authors thank José Almeida Pereira for both allowing the access to the experimental data and authorizing their use in this article.

\section{REFERENCES}

Baker, R. J. (1978). Issues in diallel analysis. Crop Science, 18(4), 533-536. https://doi.org/10.2135/cropsci1978.0011183x001800040001x

Borghi, B., \& Perenzin, M. (1994). Diallel analysis to predict heterosis and combining ability for grain yield, yield components and bread-making quality in bread wheat ( $T$. aestivum). Theoretical and Applied Genetics, 89(7-8), 975-981. https://doi.org/10.1007/BF00224527

Christensen, R. (1996). Analysis of variance, design and regression. London, UK: Chapman \& Hall.

Christie, B. R., \& Shattuck, V. I. (1992). The diallel cross: design, analysis, and use for plant breeders. Plant Breeding Reviews, 9, 9-36.

Chukwu, S. C., Okporie, E. O., Onyishi, G. C., Ekwu, L. G., \& Nwogbaga, A. C. (2016). Application of diallel analyses in crop improvement. Agriculture and Biology Journal of North America, 7(2), 95-106. https://doi.org/10.5251/abjna.2016.7.2.95.106

Cox, D. (1982). Statistical significance tests. Diagnostic Histopathology, 22(7), 243-245. https://doi.org/10.1016/j.mpdhp.2016.06.002

Cruz, C. D., Regazzi, A. J., \& Carneiro, P. C. S. (2012). Modelos biométricos aplicados ao melhoramento genético. Viçosa, MG: Editora UFV.

Fasahat, P., Rajabi, A., Rad, J. M., \& Derera, J. (2016). Principles and utilization of combining ability in plant breeding. Biometrics \& Biostatistics International Journal, 4(1), 1-24. https://doi.org/10.15406/bbij.2016.04.00085

Gardner, C., \& Eberhart, S. (1966). Analysis and interpretation of the cultivar cross diallel and related populations. Author(s): Gardner, C. O., \& Eberhart, S. A. Published by : International Biometric Society Stable URL : http://www.jstor.org/stable/2528181 . Biometrics, 22(3), 439-452.

Gilbert, N. E. G. (1958). Diallel cross in plant breeding. Heredity, 12(4), 477-492. https://doi.org/10.1038/hdy.1958.48

Gomes, F. P. (2009). Curso de estatística experimental (15th ed.). Piracicaba, SP: Fealq.

Griffing, B. (1956). Concept of general and specific combining ability in relation to diallel crossing systems. Australian Journal of Biological Sciences, 9(4), 463. https://doi.org/10.1071/bi9560463

Hallauer, A. R., Carena, M. J., Miranda-Filho, J. B. (2010). Quantitative genetics in maize breeding. Ames, IA: The lowa State University Press.

Hayman, B. I. (1954a). The analysis of variance of diallel tables. Biometrics, (10), 235-244. 
Hayman, B. I. (1954b). The theory and analysis of diallel crosses. Genetics, (39), 789-809.

Kempthorne, O. (1956). The theory of the diallel cross. Genetics, 41(4), 451-459. https://doi.org/10.1093/genetics/41.4.451

Mutimaamba, C., MacRobert, J., Cairns, J. E., Magorokosho, C. E., Ndhlela, T., Mukungurutse, C., ... Labuschagne, M. T. (2017). Diallel analysis of acid soil tolerant and susceptible maize inbred lines for grain yield under acid and non-acid soil conditions. Euphytica, 213:88, 1-10. https://doi.org/10.1007/s10681-017-1877-5

Nassar, R. F. (1965). Effects of correlated gene distribution due to sampling on the diallel analysis. Genetics, (59), 9-20.

Nkalubo, S. T., Melis, R., Derera, J., Laing, M. D., \& Opio, F. (2009). Genetic analysis of anthracnose resistance in common bean breeding source germplasm. Euphytica, 167(3), 303-312. https://doi.org/10.1007/s10681-008-9873-4

Pereira, J. A., Morais, O. P., \& Breseghello, F. (2008). Análise da heterose de cruzamentos entre variedades de arroz-vermelho. Pesquisa Agropecuaria Brasileira, 43(9), 1135-1142. https://doi.org/10.1590/S0100-204X2008000900006

Vencovsky, R., \& Barriga, P. (1992). Genética biométrica no fitomelhoramento. Ribeirão Preto, SP: Sociedade Brasileira de Genética.

Received: May 21, 2021.

Accepted: June 3, 2021.

Published: July 7, 2021.

English by: College Language Center, Londrina, PR, Brazil. 